\title{
Molecular Dynamics Simulation and Density Functional Theory Investigation for Thiacalix[4]biscrown and its Complexes with Alkali-Metal Cations
}

\author{
Jooyeon Hong, Chewook Lee, and Sihyun Ham* \\ Department of Chemistry, Sookmyung Women's University, Seoul 140-742, Korea. *E-mail: sihyun@sookmyung.ac.kr \\ Received January 13, 2010, Accepted January 30, 2010
}

\begin{abstract}
The structural and energetic preferences of thiacalix[4] biscrown-5 with and without alkali metal ions $\left(\mathrm{Na}^{+}, \mathrm{K}^{+}, \mathrm{Rb}^{+}\right.$, and $\mathrm{Cs}^{+}$) have been theoretically investigated for the first time using molecular dynamic (MD) simulations and density functional theory (MPWB1K/6-31G(d)//B3LYP/6-31G(d)) methods. The formation of the metal ion complex by the host is mainly driven by the electrostatic attraction between crown-5 oxygens and a cation together with the minor contribution of the cation- $\pi$ interaction between two facing phenyl rings around the cation. The computed binding energies and the atomic charge distribution analysis for the metal binding complexes indicate the selectivity toward a potassium ion. The theoretical results herein explain the experimentally observed extractability order by this host towards various alkali metal ions. The physical nature and the driving forces for cation recognition by this host are discussed in detail.
\end{abstract}

Key Words: Thiacalix[4]biscrown-5, Alkali metal cations, Complexation, Density functional theory (DFT)

\section{Introduction}

Calix[4]arene $\mathbf{1}$ has been attracted numerous attention due to its potential accessibility for molecular recognition, ion transport phenomena, enzyme model building, and the construction of sensors for a wide variety of applications. ${ }^{1,2}$ Thiacalix[4]arene $\mathbf{2}$ is of particular interest since the bridging sulfur atoms in the macrocyclic cavity can provide greater dimensionality on the cavity size, functional modification, and extra binding sites for guest complexation compared to calix[4]arene. ${ }^{3-9}$ Thiacalix[4]arene can adapt four distinctive conformations as cone, partial cone, 1,2-alternate, and 1,3-alternate, as in the case of calix[4]arene. The different conformations of $\mathbf{2}$ can be executed by appropriate functionalization. Among the thiacalix[4] arene derivatives, thiacalix[4]biscrown-5 3 with crown-ether linkages in the thiacalix[4] arene cavity as synthesized (Figure 1). ${ }^{10}$ One of the most interesting features of $\mathbf{3}$ is the metal ion shuttling through the aromatic cavity. ${ }^{11,12}$ It was reported that metal ion extractabilities of several thiacalix[4]biscrown compounds were

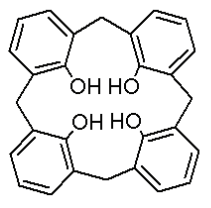

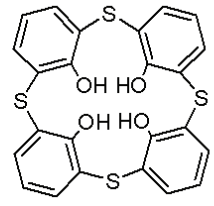

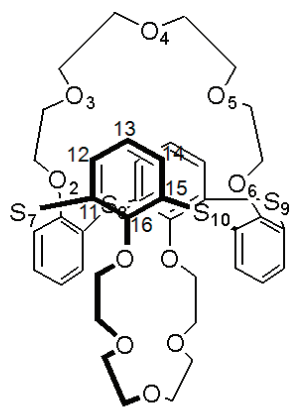

Figure 1. Schematic representation of calix[4]pyrrole 1, thiacalix[4]arene 2 and 1,3-alternate thiacalix[4]biscrown-5 3. The atom numbering in structure $\mathbf{3}$ is used for the charge analysis in Table 2. not as efficient as those of conventional calix[4]biscrowns. ${ }^{11-17}$ Nevertheless, only limited studies have been reported on the metal ion shuttling experimentally and theoretically. ${ }^{11,12,18}$ Conformational characteristics and thermodynamics stability order among different conformers of $\mathbf{2}$ were previously reported by us in comparison with those of $\mathbf{1}$ by using density functional theory (DFT) calculations. ${ }^{9}$ Despite of the phenomenological behavior of the metal ion shuttling with $\mathbf{3}$, no detailed structural and complexation studies were reported on $\mathbf{3}$ and its metal ion complexes.

Here, we report the first DFT investigation combined with molecular dynamics (MD) simulations on the conformational characteristics of $\mathbf{3}$ and compared with the experimentally determined structure. The complexation behaviors of $\mathbf{3}$ with various alkali metal ions $\left(\mathrm{Na}^{+}, \mathrm{K}^{+}, \mathrm{Rb}^{+}\right.$, and $\left.\mathrm{Cs}^{+}\right)$are also reported to understand the thermodynamic stability and binding affinities of the complexes as well as the structural changes upon complexation by using DFT calculations at the MPWB1K/6-31G(d)// B3LYP/6-31G(d) level. The major driving force for the cation binding of $\mathbf{3}$ is observed to be the electrostatic attraction between crown-5 oxygens and a cation together with the minor contribution of the cation- $\pi$ interaction between two facing phenyl rings around the cation. Theoretical understanding of the physical nature and the driving forces for cation recognition by this host may be used in a wide variety of synthetic host and chemical systems design based on thiacalix[4]arene and crown-ether derivatives which are capable of cation recognition.

\section{Computational Methods}

To search the global minimum structure for $\mathbf{3}$, an initial conformational analysis was performed by MD simulation by using the SANDER module of AMBER program ${ }^{19}$ employing parm99 force field. The molecular system was subjected to 1000 steps of conjugate gradient energy minimization, and then brought 
A. Computed structure

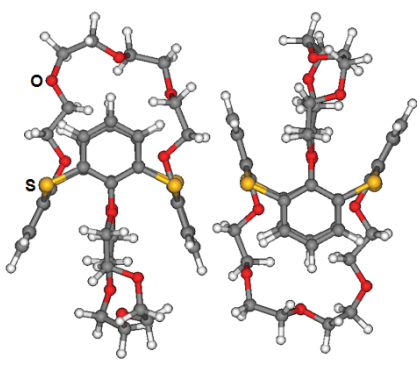

(a) Side view $\quad$ (b) $90^{\circ}$ rotated view

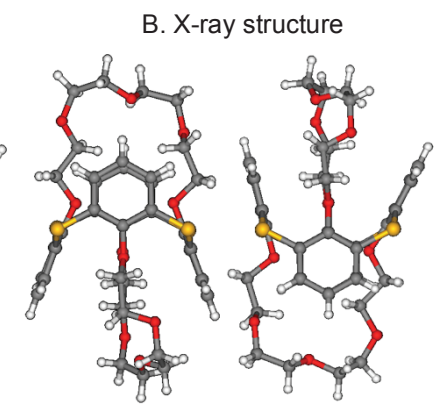

(a) Side view (b) $90^{\circ}$ rotated view
Figure 2. The computed structure at the B3LYP/6-31G(d) level (A) and X-ray determined (B) structure of $\mathbf{3}$. The X-ray structure was taken from ref. 10. Side view and 90 degree rotated view are shown for each structure.

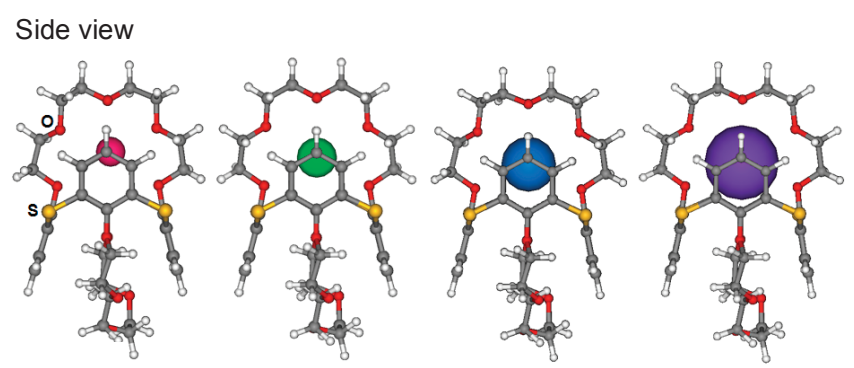

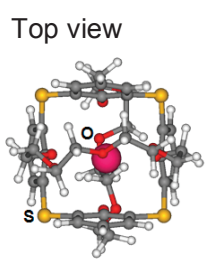

(a)

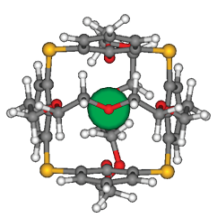

(b)

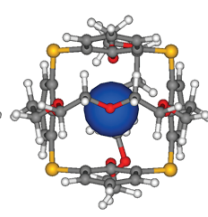

(c)

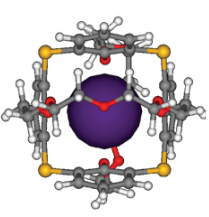

(d)
Figure 3. The optimized structures of $\mathbf{3}$ with alkali metal ions computed at the B3LYP/6-31G(d) (except alkali metal ions computed at the LANL2DZ basis set): complex with (a) Sodium ion, (b) Potassium ion, (c) Rubidium ion, and (d) Cesium ion. Top views and side views are displayed for each complex.

into an equilibrium state for $100 \mathrm{ps}$ using the Berendsen coupling algorithm. ${ }^{20}$ In all calculations, an $8.0 \AA$ non-bonded interaction cut-off was used and non-bonded pair lists were updated energy 20 integration steps. A 2 fs time step was used and the simulation was performed for $1 \mathrm{~ns}$ at $500 \mathrm{~K}$. The structures were saved every 5 ps for analyses. Total 200 structures were collected from the MD simulation trajectory, which were subjected for the geometry optimizations with AM1 semi-empirical method ${ }^{21}$ to find the energy minima that would be used as initial structures for a high-level geometry optimization. Then we used DFT method with B3LYP/6-31G(d) level ${ }^{22}$ to search the global minimum geometry in a gas phase.

The structures of metal ion complex were calculated by using B3LYP/6-31G(d) level. The LANL2DZ basis set ${ }^{23}$ was applied to alkali metal ions except $\mathrm{Na}^{+}$ion. Despite of the superior performance of DFT methods in numerous energy assessments and molecular structure predictions, there is increasing awareness that $\mathrm{B}^{2} \mathrm{LYP} \mathrm{P}^{22}$ can fail badly in estimating the energies of non-bonded interactions, hydrogen bonded systems, and larger molecules. ${ }^{24-27}$ To overcome these disadvantages, some of the hybrid meta-GGA such as MPWB1K and MPW1B95 were developed. ${ }^{28,29}$ These can provide more accurate assessment of weakly bound systems and better descriptions of intramolecular non-bonded interactions. The atomic charge density calculations were computed by natural population analysis (NPA) method ${ }^{30}$ at the B3LYP/6-31G(d) level except for the alkali-metal ions which were computed by LANL2DZ basis set. All energies discussed in the paper are at the MPWB1K/ 6-31G(d)//B3LYP/6-31G(d) level unless otherwise noted. All quantum chemical calculations were performed by using GAUSSIAN 03 program. ${ }^{31}$

\section{Results and Discussion}

The most stable conformation for $\mathbf{1}$ or $\mathbf{2}$ is the cone conformation among four major conformations due to the cyclic array of the intra-molecular hydrogen bonds between hydroxyl groups. ${ }^{9}$ The first synthesis of $\mathbf{3}$ was reported in 2001 and X-ray diffraction study revealed that 3 adopts a 1,3-alternate conformation in the solid state. ${ }^{10}$ Due to our previous DFT calculation at the MPWB1K/6-311G**//B3LYP/6-311G** level, the 1,3-alternate of $\mathbf{2}$ is located to be $10.1 \mathrm{kcal} / \mathrm{mol}$ higher in energy than that of the cone. ${ }^{9}$ The conformation of $\mathbf{3}$ was reported to be 1,3 -alternate by $\mathrm{NMR}^{10,11}$ and $\mathrm{X}$-ray ${ }^{10}$ studies presumably due to the preferential dipole moment. In Figure 2, the computed global minimum structure (A) and X-ray structure (B) for $\mathbf{3}$ are displayed. The X-ray structure was taken from reference 10. The side views and the $90^{\circ}$ rotated views are available for each structure to display the upward and the downward crown-ether rings clearly. Noticeably, the theoretical (A) and experimental (B) structures are in excellent agreement except for the fact that $\mathrm{A}$ has a slightly larger calix tube than $\mathrm{B}$. The root-meansquare deviation (RMSD) between A and B structures is $0.31 \AA$. The distances between two phenolic oxygens in the upward and the downward cavities are 4.30 and $4.36 \AA$ in $\mathrm{A}$, whereas those are 4.06 and $4.16 \AA$ in $\mathrm{B}$, respectively. In the X-ray structure, the tube size is a bit narrower due to the packing force. The NPA charge calculation ${ }^{30}$ shows that the average atomic charges on oxygen and on sulfur in A are $-0.578 \mathrm{e}$ and $0.308 \mathrm{e}$, respectively (Table 1). It indicates that the ether oxygens would involve in cation recognition, whereas the slightly positive sulfur atoms may not play a role in cation recognizing.

The complexation study of $\mathbf{3}$ was experimentally performed after its synthesis that the metal ion extractabilities of $\mathbf{3}$ were found to be lower than that of conventional calix[4]biscrown. ${ }^{11,14,15}$ Moreover, this weak metal binding character of $\mathbf{3}$ was confirmed by the observation of the metal ion shuttling through the thiacalix[4] biscrown tube. ${ }^{11,12}$ This intrigued us to perform the detailed DFT calculations on the metal ion complexes of $\mathbf{3}$ to understand the thermodynamic stability of the complexes of $\mathbf{3}$ and the driving force for the cation recognition.

The geometry optimized structures for the complexes of $\mathbf{3}$ with four different alkali metal ions $\left(\mathrm{Na}^{+}, \mathrm{K}^{+}, \mathrm{Rb}^{+}\right.$and $\left.\mathrm{Cs}^{+}\right)$are shown in Figure 3. The binding energies for those complexes are summarized in Table 2. The NPA computed atomic charges for a free host $\mathbf{3}$ and four different complexes of $\mathbf{3}$ are summariz- 
Table 1. The NPA computed atomic charges for 3 and its complexes with four alkali metals at the B3LYP/6-31G(d) level of theory. Atom numbering is shown in the structure $\mathbf{3}$ in Figure 1.

\begin{tabular}{crrrrr}
\hline Atom & $\mathbf{3}$ & $\mathbf{3}+\mathrm{Na}^{+}$ & $\mathbf{3}+\mathrm{K}^{+}$ & $\mathbf{3}+\mathrm{Rb}^{+}$ & ${\mathbf{3}+\mathrm{Cs}^{+}}^{+}$ \\
\hline M1 & & 0.902 & 0.898 & 0.910 & 0.921 \\
O2 & -0.562 & -0.598 & -0.608 & -0.606 & -0.605 \\
O3 & -0.590 & -0.625 & -0.617 & -0.611 & -0.609 \\
O4 & -0.593 & -0.642 & -0.617 & -0.615 & -0.617 \\
O5 & -0.585 & -0.635 & -0.617 & -0.612 & -0.613 \\
O6 & -0.561 & -0.610 & -0.610 & -0.608 & -0.606 \\
S7 & 0.305 & 0.325 & 0.326 & 0.323 & 0.328 \\
S8 & 0.313 & 0.322 & 0.322 & 0.319 & 0.312 \\
S9 & 0.312 & 0.327 & 0.330 & 0.326 & 0.320 \\
S10 & 0.303 & 0.325 & 0.324 & 0.321 & 0.316 \\
C11 & -0.224 & -0.235 & -0.236 & -0.239 & -0.240 \\
C12 & -0.230 & -0.220 & -0.239 & -0.240 & -0.242 \\
C13 & -0.235 & -0.268 & -0.253 & -0.252 & -0.250 \\
C14 & -0.227 & -0.241 & -0.240 & -0.239 & -0.239 \\
C15 & -0.217 & -0.242 & -0.238 & -0.241 & -0.241 \\
C16 & 0.322 & 0.326 & 0.323 & 0.321 & 0.315 \\
\hline
\end{tabular}

Table 2. The computed binding energies $(\mathrm{kcal} / \mathrm{mol})$ for complexes of 3 with alkali metal ions (except sodium ion) are listed at the B3LYP/6-31G(d) and MPWB1K/6-31G(d)//B3LYP/6-31G(d) level of theory. Dipole moments (in Debye) calculated at the B3LYP/ 6-31G(d) level are listed.

\begin{tabular}{lccc}
\hline & $\begin{array}{c}\mathrm{B} 3 \mathrm{LYP} / \\
6-31 \mathrm{G}(\mathrm{d})\end{array}$ & $\begin{array}{c}\mathrm{MPWB}^{6} \mathrm{~K} / \\
6-31 \mathrm{G}(\mathrm{d})^{a}\end{array}$ & $\begin{array}{c}\text { dipole } \\
\text { moment }\end{array}$ \\
\hline${\text { Complex with } \mathrm{K}^{+}}^{+}$ & -40.5 & -58.4 & 6.3 \\
${\text { Complex with } \mathrm{Rb}^{+}}^{+}$ & -29.6 & -48.0 & 5.2 \\
Complex with $\mathrm{Cs}^{+}$ & -12.9 & -32.0 & 4.7 \\
\hline
\end{tabular}

${ }^{a}$ Geometry optimized using B3LYP/6-31G(d) level. Binding energy (kcal/ $\mathrm{mol})=\mathrm{E}_{\text {complex }}-\left(\mathrm{E}_{\text {host }}+\mathrm{E}_{\text {alkali metal ion }}\right)$

ed in Table 1. Upon complexation with alkali metal cation, the major structural change from a free state 3 to ion-binding complex forms is the reorientation of the crown-ether ring geometry to maximize the electrostatic interaction between a cation and ether oxygen atoms. The detailed structural changes and the binding energies and the charge distributions upon complexation are discussed below.

Experimentally, 3 displays no extractability toward $\mathrm{Na}^{+}$ ion. ${ }^{11,14}$ Nevertheless, we located the global minimum structure for $3+\mathrm{Na}^{+}$complex to compare with other metal complexes. For the $3+\mathrm{Na}^{+}$complex in Figure 3, the distances between two phenolic oxygens in the upward and the downward cavities are 4.92 and $5.07 \AA$, respectively. Due to maximize the electrostatic interaction between ether oxygens and sodium ion, all five oxygens in the upward crown ring are pointed inside of the cavity with the average distance $\left(\mathrm{r}\left(\mathrm{Na}^{+}-\mathrm{O}\right)\right)$ of $2.73 \AA$. Although $\mathrm{Na}^{+}$is too small for the crown-5 ring to coordinate tightly regarding the key-and-lock rule ${ }^{32}, \mathrm{Na}^{+}$is enough to attract the ether oxygens located inside the cavity. ${ }^{15}$ Since LANL2DZ basis set is not available for the $\mathrm{Na}^{+}$ion, we couldn't compute the binding energy for $3+\mathrm{Na}^{+}$complex and compare it with other complexes.

3 exhibits the highest extractability toward $\mathrm{K}^{+}$ion among various alkali metal ions by two-phase picrate extraction method. ${ }^{11,14,15}$ For the $3+\mathrm{K}^{+}$complex, the distances between crown ether oxygens and $\mathrm{K}^{+}$ion are $2.89,2.88,2.87,2.88$, and $2.87 \AA$ (average $=2.88 \AA$ ) Also, the distances between two phenolic oxygens in the upward and the downward cavities are 5.08 and $5.03 \AA$, respectively. The atomic charge distributions for 3 and its metal ion complexes are summarized in Table 2. Based on the charge density calculation, the atomic charge distributions for $\mathbf{3}$ are mostly affected by the potassium ion binding compared to other metals. Moreover, most of the changes in atomic charges are found in ether oxygens that the electronegative oxygens in the crown ring are most attributable for the cation recognition. It is also notable that the charges of two adjacent phenyl rings next to a cation are perturbed by cation binding due to the cation- $\pi$ interaction. The contribution of the cation- $\pi$ interaction holds a minor contribution on metal binding, which is in agreement with the previous report on similar systems. ${ }^{33}$ Since the $\mathrm{K}^{+}$ion is recognized by one side of the complex, the dipole moment of the $3+\mathrm{K}^{+}$complex is computed to be $6.3 \mathrm{D}$ which is quite large compared to $0.8 \mathrm{D}$ for the free host $\mathbf{3}$.

Based on the geometry and the atomic charge distribution analyses, the potassium ion is mainly recognized by strong electrostatic interaction with negative ether oxygens along with a minor contribution by cation- $\pi$ interaction with adjacent phenyl rings. This is in good agreement with the previous NMR experimental result for thiacalix [4] biscrown-5;6 complex with potassium ion. ${ }^{10}$ The binding energy for $3+\mathrm{K}^{+}$complex is computed to be $-58.4 \mathrm{kcal} / \mathrm{mol}$ (Table 2). This is stronger than those for $\mathrm{Rb}^{+}$or $\mathrm{Cs}^{+}$ion, yet quite weaker compared to the $-72.0 \mathrm{kcal} / \mathrm{mol}$ (calculated at the MP2/6-31+G(d)) for $\mathrm{K}^{+}$ion and 18-crown- 6 . $^{34}$ The relatively weak binding affinity between potassium ion and $\mathbf{3}$ is attributable for the potassium ion shuttling phenomenon in the calix tube observed experimentally.

Experimentally, 3 exhibits $\mathrm{Rb}^{+}$metal binding ability although the extractability is not as good as that for the potassium. ${ }^{11}$ For the $3+\mathrm{Rb}^{+}$complex, the overall shape of the energy minimum complex is similar to $3+\mathrm{K}^{+}$complex. The distances between five crown ether oxygens and $\mathrm{Rb}^{+}$ion are 2.91, 3.00, 2.96, 3.00, and $2.90 \AA$ (average $=2.95 \AA$ ) The distances between two phenolic oxygens in the upward and the downward cavities are 5.24 and $5.02 \AA$, respectively. The binding energy for $3+\mathrm{Rb}^{+}$ complex is calculated to be $-48.0 \mathrm{kcal} / \mathrm{mol}$ which is weaker than that for $3+\mathrm{K}^{+}$complex. Based on the structure, thermodynamic stability, and charge analysis, the cation recognition in $3+\mathrm{Rb}^{+}$complex is mainly driven by the electrostatic attractions between ether oxygens and a cation. The metal ion shu$\mathrm{ttling}$ may not be detected due to the bigger size of the $\mathrm{Rb}^{+}$ion inside the calix tube of $\mathbf{3}$.

The global minimum structure for $3+\mathrm{Cs}^{+}$complex is located with the distances between five crown ether oxygens and $\mathrm{Rb}^{+}$ ion to be 2.98, 3.11, 3.07, 3.12, and $2.97 \AA$ (average $=3.05 \AA$ ). The distances between two phenolic oxygens in the upward and the downward cavities are 5.48 and $5.01 \AA$, respectively. Due to the size of $\mathrm{Cs}^{+}$ion, the upward cavity in $3+\mathrm{Cs}^{+}$complex expands the most among four complexes discussed in this paper. The binding energy is computed to be $-32.0 \mathrm{kcal} / \mathrm{mol}$ for $3+\mathrm{Cs}^{+}$ complex. Due to the large size of $\mathrm{Cs}^{+}$ion, the formation of the $3+\mathrm{Cs}^{+}$complex may be hindered kinetically. The extractability 
for $\mathrm{Cs}^{+}$ion by $\mathbf{3}$ was almost zero experimentally. ${ }^{11}$

\section{Conclusions}

The global minimum structure for free ligand $\mathbf{3}$ and its complexes with four alkali metals $\left(\mathrm{Na}^{+}, \mathrm{K}^{+}, \mathrm{Rb}^{+}\right.$, and $\left.\mathrm{Cs}^{+}\right)$have been computed by performing MD simulations and DFT calculations at the B3LYP/6-31G(d) and MPWB1K/6-31G(d)// B3LYP/6-31G(d) level. The computed structure for 3 is in good agreement with the $\mathrm{X}$-ray determined structure. Upon complexation with alkali metal cations, the major structural change from a free state 3 to cation-binding complex is the reorientation of the crown-ether ring geometry to maximize the electrostatic interaction between a cation and ether oxygen atoms. The structural changes and the atomic charge distribution analyses provide that the cation recognition is mainly attributed by the electrostatic interaction between ether oxygens and a metal ion together with the minor contribution of the cation- $\pi$ interaction between two facing phenyl rings around the metal ion. The theoretical results herein confirm and explain experimentally observed extractability order by $\mathbf{3}$ towards various alkali metal ions. The energetic and structural characteristics of $\mathbf{3}$ with and without alkali-metal cations are executed for the first time using DFT method. This study contributes to understand the driving force and binding sites for the complexation of thiacalix[4]biscrown-5 and provides insights for the host design for cation recognition.

Acknowledgments. This work was supported by the Sookmyung Women's University Research Grant, 2007. We thank the authors of reference 10 for kindly providing the $3 \mathrm{D}$ coordinates of the X-ray structure of $\mathbf{3}$.

\section{References}

1. Gutsche, C. D. Calixarenes; Royal Society of Chemistry: Cambridge, 1989

2. Vicens, J.; Böhmer, V. Calixarenes: a Versatile Class of Macrocyclic Compounds; Springer: 1990.

3. Akdas, H.; Bringel, L.; Graf, E.; Hosseini, M. W.; Mislin, G.; Pansanel, J.; Cian, A. D.; Fischer, J. Tetrahedron Lett. 1998, 39, 2311.

4. Iki, N.; Miyano, S. J. Inclu. Phenom. Macro. Chem. 2001, 41, 99.

5. Shokova, E. A.; Kovalev, V. V. Russ. J. Chem. Bull. 2003, 39, 13.

6. Lhoták, P. Eur. J. Org. Chem. 2004, 2004, 1675.

7. Morohashi, N.; Narumi, F.; Iki, N.; Hattori, T.; Miyano, S. Chem. Rev. 2006, 106, 5291.

8. Suwattanamala, A.; Magalhães, A. L.; Gomes, J. A. N. F. Chem. Phys. Lett. 2004, 385, 368.

9. Hong, J.; Ham, S. Tetrahedron Lett. 2008, 49, 2393.

10. Lamare, V.; Dozol, J. F.; Thuery, P.; Nierlich, M.; Asfari, Z.; Vicens, J. J. Chem. Soc. Perkin Trans.2 2001, 1920.

11. Lee, J. K.; Kim, S. K.; Bartsch, R. A.; Vicens, J.; Miyano, S.; Kim, J. S. J. Org. Chem. 2003, 68, 6720 .

12. Kim, S. K.; Lee, J. K.; Lee, S. H.; Lim, M. S.; Lee, S. W.; Sim, W.;
Kim, J. S. J. Org. Chem. 2004, 69, 2877.

13. Csokai, V.; Grun, A.; Parlagh, G.; Bitter, I. Tetrahedron Lett. 2002, 43, 7627.

14. Grun, A.; Csokai, V.; Parlagh, G.; Bitter, I. Tetrahedron Lett. 2002, 43,4153 .

15. Bouhroum, S.; Arnaud-Neu, F.; Asfari, Z.; Vicens, J. Russ. Chem. Bull. 2004, 53, 1544.

16. van Leeuwen, F. W. B.; Beijleveld, H.; Miermans, C. J. H.; Huskens, J. Verboom, W.; Reinhoudt, D. N. Anal. Chem. 2005, 77, 4611.

17. Kumar, M.; Dhir, A.; Bhalla, V. Tetrahedron 2009, 65, 7510.

18. Yang, K. Y.; Kang, K. D.; Park, Y. H.; Koo, I. S.; Lee, I. Chem. Phys. Lett. 2003, 381, 239.

19. Case, D. A.; Darden, T. A.; Cheatham, III, T. E.; Simmerling, C. L.; Wang, J.; Duke, R. E.; Luo, R.; Merz, K. M.; Pearlman, D. A.; Crowley, M.; Walker, R. C.; Zhang, W.; Wang, B.; Hayik, S.; Roitberg, A.; Seabra, G.; Wong, K. F.; Paesani, F.; Wu, X.; Brozell, S.; Tsui, V.; Gohlke, H.; Yang, L.; Tan, C.; Mongan, J.; Hornak, V.; Cui, G.; Beroza, P.; Mathews, D. H.; Schafmeister, C.; Ross, W. S.; Kollman, P. A. AMBER 9; University of California, San Francisco, 2006.

20. Berendsen, H. J. C.; Postma, J. P. M.; van Gunsteren, W. F.; DiNola, A.; Haak, J. R. J. Chem. Phys. 1984, 81, 3684.

21. Dewar, M.; Zoebisch, E. G.; Healy, E. F. J. Am. Chem. Soc. 1985 , 107,3902

22. Becke, A. D. J. Chem. Phys. 1993, 98, 5648.

23. Hay, P. J.; Wadt, W. J. Chem. Phys. 1985, 82, 299.

24. Lynch, B. J.; Fast, P. L.; Harris, M.; Truhlar, D. G. J. Phys. Chem. A 2000, 104, 4811.

25. Tsuzuki, S.; Luthi, H. P. J. Chem. Phys. 2001, 114, 3949.

26. Zhao, Y.; Tishchenko, O.; Truhlar, D. G. J. Phys. Chem. B 2005, 109, 19046.

27. Schreiner, P. R.; Fokin, A. A.; Pascal, D. G.; de Meijere, A. Org. Lett. 2006, 8, 3635.

28. Zhao. Y.; Truhlar, D. G. J. Phys. Chem. A 2004, 108, 6908.

29. Dkhissi, A.; Blossey, R. Chem. Phys. Lett. 2007, 439, 35.

30. Reed, A. E.; Curtiss, L. A.; Weinhold, F. Chem. Rev. 1988, 88, 899.

31. Frisch, M. J.; Trucks, G. W.; Schlegel, H. B.; Scuseria, G. E.; Robb, M. A.; Cheeseman, J. R.; Montgomery, J. A., Jr.; Vreven, T.; Kudin, K.; Burant, J. C.; Millam, J. M.; Iyengay, S. S.; Tomasi, J.; Barone, V.; Mennucci, B.; Cossi, M.; Scalmani, G.; Rega, N.; Petersson, G. A.; Nakatsuji, H.; Hada, M.; Ehara, M.; Toyota, K.; Fukuda, R.; Hasegawa, J.; Ishida, M.; Nakajima, T.; Honda, Y.; Kitao, O.; Nakai, H.; Klene, M.; Li, X.; Knox, J. E.; Hratchian, H. P.; Cross, J. B.; Adamo, C.; Jaramillo, J.; Comperts, R.; Startmann, R. E.; Yazyev, O.; Austin, A. J.; Cammi, R.; Pomelli, C.; Ochterski, J. W.; Ayala, P. Y.; Morokuma, K.; Voth, G. A.; Salvador, P.; Dannenbuerg, J. J.; Zakrzewski, V. G.; Dapprich, S.; Daniels, A. D.; Strain, M. C.; Farkas, O.; Malick, D. K.; Rabuck, A. D.; Raghavachari, K.; Foresman, J. B.; Ortiz, J. V.; Cui, Q.; Baboul, A. G.; Clifford, S.; Cioslowski, J.; Stefanov, B. B.; Liu, G.; Liashenko, A.; Piskorz, P.; Komaromi, I.; Martin, R. L.; Fox, D. J.; Keith, T.; Al-Laham, M. A.; Peng, C. Y.; Nanayakkara, A.; Challacombe, M.; Gill, P. M. W.; Johnson, B.; Chem, W.; Wong, M. W.; Gonzalez, C.; Pople, J. A. Gaussian03, revision C.02; Gaussian, Inc.: Wallingford, CT, 2004.

32. Pedersen, C. J. Am. Chem. Soc. 1970, 92, 391

33. Zheng, X.; Wang, X.; Yi, S.; Wang, N.; Peng, Y. J. Comput. Chem. $\mathbf{2 0 0 9}$, in press.

34. Glendening, E. D.; Feller, D.; Thompson, M. A. J. Am. Chem. Soc. 1994, 116, 10657 